\title{
Cerebellar learning distinguishes inflammatory neuropathy with and without tremor OPEN
}

Petra Schwingenschuh, MD*

Tabish A. Saifee, MRCP* Petra Katschnig-Winter, MD

Mary M. Reilly, FRCP

Michael P. Lunn, FRCP

Hadi Manji, FRCP

Maria Aguirregomozcorta, MD

Reinhold Schmidt, MD

Kailash P. Bhatia, FRCP

John C. Rothwell, PhD

Mark J. Edwards, PhD

Correspondence to

Dr. Edwards:

m.j.edwards@ucl.ac.uk

Supplemental data at www.neurology.org

\section{ABSTRACT}

Objectives: This study aims to investigate if patients with inflammatory neuropathies and tremor have evidence of dysfunction in the cerebellum and interactions in sensorimotor cortex compared to nontremulous patients and healthy controls.

Methods: A prospective data collection study investigating patients with inflammatory neuropathy and tremor, patients with inflammatory neuropathy without tremor, and healthy controls on a test of cerebellar associative learning (eyeblink classical conditioning), a test of sensorimotor integration (short afferent inhibition), and a test of associative plasticity (paired associative stimulation). We also recorded tremor in the arms using accelerometry and surface EMG.

Results: We found impaired responses to eyeblink classical conditioning and paired associative stimulation in patients with neuropathy and tremor compared with neuropathy patients without tremor and healthy controls. Short afferent inhibition was normal in all groups.

Conclusions: Our data strongly suggest impairment of cerebellar function is linked to the production of tremor in patients with inflammatory neuropathy. Neurology ${ }^{\circledR}$ 2013;80:1867-1873

\section{GLOSSARY}

ADM = abductor digiti minimi; $\mathbf{A N O V A}=$ analysis of variance; $\mathbf{A P B}=$ abductor pollicis brevis; $\mathbf{C I D P}=$ chronic inflammatory demyelinating polyradiculoneuropathy; $\mathbf{C R}=$ conditioned blink responses; $\mathbf{E B C C}=$ eyeblink classical conditioning; FDI = first dorsal interossei; IgMPN = immunoglobulin M paraproteinaemic neuropathy; $\mathbf{M E P}=$ motor evoked potential; $\mathbf{M M N C B}=$ multifocal motor neuropathy with conduction block; MRC = Medical Research Council; ONLS = Overall Neuropathy Limitation Scale; PAS = paired associative stimulation; PF = peak tremor frequency; SAI = short afferent inhibition; TMS = transcranial magnetic stimulation; TP = total power of the spectra between 1 and $30 \mathrm{~Hz}$ used as surrogate measure of tremor amplitude; US = unconditioned stimulus; $\mathbf{W E}=$ wrist extensor muscles.

Inflammatory mediated neuropathies are common and potentially treatable. ${ }^{1}$ Tremor occurs with immunoglobulin M paraproteinaemic neuropathy $(\operatorname{IgMPN})^{2-4}$ and less commonly in other inflammatory neuropathies. ${ }^{5}$ It has been suggested that temporally distorted peripheral inputs reach a normally functioning central processor, such as the cerebellum, which is misled into producing a delayed second agonist burst and tremor. ${ }^{6-8}$ The involvement of the cerebellum in neuropathic tremor is supported by functional imaging abnormalities. ${ }^{9}$ There does not seem to be a straightforward relationship between the development of tremor and conduction velocity. ${ }^{10}$ Further, no relationship seems to exist between tremor and the severity of neuropathy as assessed by proprioceptive loss, weakness, or fatigue. ${ }^{11,12}$ However, we have shown that although conduction velocity does not predict the presence of tremor, it is correlated with its severity for those in whom tremor is present. ${ }^{5}$ This indicates a second mechanism may be necessary to produce tremor.

Here we set out to explore aspects of CNS physiology in tremulous and nontremulous patients with inflammatory neuropathies compared to healthy controls. We hypothesized that the central compensation needed to account for delays caused by the peripheral neuropathy would most likely depend on plastic changes within the cerebellum and connections that mediate interaction between sensory and motor systems and therefore that patients with tremor would have evidence

\footnotetext{
*These authors contributed equally to this work.

From the Sobell Department of Motor Neuroscience and Movement Disorders (P.S., T.A.S., P.K.-W., M.A., K.P.B., J.C.R., M.J.E.) and MRC Centre for Neuromuscular Diseases, Department of Molecular Neurosciences (M.M.R., M.P.L., H.M.), UCL Institute of Neurology, Queen Square, London, UK; and Department of Neurology (P.S., P.K.-W., R.S.), Medical University of Graz, Graz, Austria.

Go to Neurology.org for full disclosures. Funding information and disclosures deemed relevant by the authors, if any, are provided at the end of the article. This is an open access article distributed under the Creative Commons Attribution License, which permits unrestricted use, distribution, and reproduction in any medium, provided the original work is properly cited.
} 
of dysfunction in the cerebellum and interactions in sensorimotor cortex compared to nontremulous patients and controls.

METHODS Subjects. Eighteen out of 43 consecutive patients published recently ${ }^{5}$ with a diagnosis of inflammatory neuropathy (chronic inflammatory demyelinating polyradiculoneuropathy [CIDP], multifocal motor neuropathy with conduction block [MMNCB], or IgMPN) agreed to take part in all or just parts of the study. The latter depended on contraindications to electrical/magnetic stimulation and on the cumulative length of study sessions.

Patients were divided into tremulous and nontremulous depending on whether arm tremor was clinically detectable. The Fahn-Tolosa-Marin scale, ${ }^{13}$ a summed Medical Research Council score $^{14}$ (MRC score; maximum 70), a sensory score ${ }^{15}$ (maximum 56), and the Overall Neuropathy Limitation Scale ${ }^{16}$ (ONLS; maximum 12) were performed.

Ten tremulous patients (mean age 60.0 [9.7] years; mean disease duration 12.5 [8.2] years; total sensory score 41.7 [13.8]; total MRC score 65.3 [4.2]; ONLS score 3.6 [1.3]) were studied. They were compared with 8 nontremulous patients who did not differ in these characteristics (mean age $63.3[8.3]$ years $[p=0.46]$; mean disease duration $14.1[10.6]$ years $[p=0.72]$; total sensory score $42.0[16.1]$ $[p=0.97]$; total MRC score 63.2 [9.0] [ $p=0.59]$; ONLS score 4.2 [1.2] $[p=0.38]$ ) (table 1). We also recruited 9 healthy age-matched controls (mean age $59.0[7.7]$ years $[p=0.54]$ ).

\begin{tabular}{|c|c|c|c|c|c|c|}
\hline \multicolumn{2}{|l|}{ Table 1} & \multicolumn{5}{|c|}{ Demographics and clinical characteristics } \\
\hline Age, $y$ & Sex & Disease & $\begin{array}{l}\text { Disease } \\
\text { duration, y }\end{array}$ & $\begin{array}{l}\text { FTM } \\
\text { score }\end{array}$ & Group & Study \\
\hline 51 & M & CIDP & 3 & 9 & $\mathrm{~T}$ & $T, E, S, P$ \\
\hline 66 & M & CIDP & 11 & 20 & T & $E, S, P$ \\
\hline 51 & M & CIDP & 9 & 13 & T & $T, E, S, P$ \\
\hline 63 & M & CIDP & 30 & 17 & $\mathrm{~T}$ & $T, E, S, P$ \\
\hline 74 & M & CIDP & 7 & 13 & $\mathrm{~T}$ & $T, E, P$ \\
\hline 70 & M & CIDP & 14 & 17 & $\mathrm{~T}$ & $T, E, P$ \\
\hline 64 & M & MMNCB & 12 & 2 & $\mathrm{~T}$ & $\mathrm{~T}, \mathrm{E}$ \\
\hline 56 & M & MMNCB & 22 & 29 & T & $\mathrm{T}, \mathrm{E}$ \\
\hline 76 & M & IgM (anti-MAG positive) & 13 & 37 & $\mathrm{~T}$ & $\mathrm{~T}, \mathrm{~S}, \mathrm{P}$ \\
\hline 62 & M & IgM (anti-MAG negative) & 4 & 43 & $\mathrm{~T}$ & $T, E, S, P$ \\
\hline 62 & M & CIDP & 7 & - & NT & $E, S, P$ \\
\hline 51 & M & CIDP & 28 & - & NT & $E, S, P$ \\
\hline 77 & $\mathrm{~F}$ & CIDP & 15 & - & NT & $E, S, P$ \\
\hline 48 & M & CIDP (IgG paraprotein) & 7 & - & NT & $S, P$ \\
\hline 67 & $\mathrm{~F}$ & CIDP & 9 & - & NT & $E, P$ \\
\hline 51 & $\mathrm{~F}$ & MMNCB & 33 & - & NT & $E$ \\
\hline 61 & M & IgM (anti-MAG negative) & 6 & - & NT & E \\
\hline 63 & $\mathrm{~F}$ & $\begin{array}{l}\text { IgM kappa (anti-MAG positive) } \\
\text { lymphoblastic lymphoma }\end{array}$ & 8 & - & NT & $E, S$ \\
\hline
\end{tabular}

Abbreviations: FTM $=$ Fahn-Tolosa-Marin total score (0 [minimum] to 4 points [maximum severity] are assigned for tremor amplitude under a variety of conditions and 0-4 points for severity in daily activities); group NT = nontremulous; group $\mathrm{T}=$ tremulous; study $\mathrm{E}=$ eyeblink classical conditioning; study $\mathrm{P}=$ paired associative stimulation; study $\mathrm{S}=$ short afferent inhibition; study $\mathrm{T}=$ tremor analysis.
Standard protocol approvals, registrations, and patient consents. Before inclusion in the study, written informed consent was obtained from all participants. This study was approved by the local Research Ethics Committee.

Electrophysiologic evaluation. Surface EMG recordings were made with $\mathrm{Ag}-\mathrm{AgCl}$ surface electrodes using a belly-tendon montage. Data were stored in a computer for display and off-line analyzed using Signal version 4.00 (and Spike version 2 for tremor analyses).

Accelerometry and EMG for tremor. Nine patients with tremor (5 CIDP, 2 MMNCB, 2 IgMPN) took part in this evaluation. A triaxial accelerometer transducer (sensitivity $\pm 100 \mathrm{mV} / \mathrm{G}$ ) was attached to the dorsal surface of the middle phalanx of the index fingers. EMG recordings were made of wrist extensor muscles (WE), wrist flexors, abductor pollicis brevis (APB), and biceps brachii bilaterally. Recordings were performed 1) with arms relaxed (rest), 2) with arms/wrists outstretched at shoulder level (posture), 3) with a 500-g mass attached to the wrists (loading), and 4) while performing a goaldirected task (action). Accelerometry and EMG were recorded and analyzed for 30 seconds in each condition.

Blink reflex and eyeblink classical conditioning. Three agematched groups were examined: 9 healthy controls, 7 nontremulous patients (4 CIDP, 1 MMNCB, 2 IgMPN), 9 tremulous patients (6 CIDP, 2 MMNCB, 1 IgMPN). Tremulous and nontremulous patients did not differ in age $(p=0.97)$, disease duration $(p=$ $0.59)$, total sensory score $(p=0.72)$, MRC score $(p=0.63)$, or ONLS score $(p=0.26)$.

Blink reflex and R2 blink reflex recovery cycle were assessed in all subjects according to a previously described protocol. ${ }^{17}$

Eyeblink classical conditioning (EBCC) is an associative learning paradigm, dependent on the cerebellum for acquisition. ${ }^{18}$ The conditioning stimulus (CS) was a loud $(50 \mathrm{~dB}$ above auditory threshold) $2,000 \mathrm{~Hz}$ tone lasting $400 \mathrm{~ms}$ played via binaural headphones. The CS inconsistently produced an acoustic startle response ("alpha blink") occurring within $200 \mathrm{~ms}$ after the CS. An electrical stimulus (unconditioned stimulus [US]; $200 \mu$ s pulse width at $5 \times$ sensory threshold) was given to the left supraorbital nerve $400 \mathrm{~ms}$ after the CS, eliciting a blink reflex (unconditioned response).

Repeated pairs of CS and US at $400 \mathrm{~ms}$ intervals yield conditioned blink responses (CR) occurring within $200 \mathrm{~ms}$ before the US (see figure e-1 on the Neurology ${ }^{\circledR}$ Web site at www.neurology.org). EMG was recorded bilaterally from orbicularis oculi. Conditioning consisted of 7 acquisition blocks (each consisting of 9 CS-US pairs, 1 US only, 1 CS only trial). An eighth and ninth block consisted of 11 CS-only trials to measure extinction.

Short afferent inhibition and paired associative stimulation. Both short afferent inhibition (SAI) and paired associative stimulation (PAS) rely on precisely timed interactions between sensory afferents and motor cortical stimulation. In healthy subjects, these interactions occur at specific times related to the N20 response. We expected N20 responses to be delayed in our patients and therefore we evaluated N20 latency in each subject. One patient had to be excluded because N20 could not be identified. N20 could be measured in all other subjects studied (expressed as mean [SD]; healthy controls 20.3 [1.5]; neuropathic tremor 33.8 [11.5]; no tremor 32.6 [6.6]).

EMG recordings were made from the abductor $\mathrm{APB}$, first dorsal interossei (FDI), and abductor digiti minimi (ADM) muscles of the right side. Test responses in the target muscles were evoked by transcranial magnetic stimulation (TMS) of the left primary motor cortex applied through Magstim 200 magnetic stimulators with a monophasic current waveform, connected to a figure of 8 coil. Standard techniques were used to identify the 
motor "hot spot" and resting motor thresholds. ${ }^{19}$ Electrical stimulation was applied to the median nerve at the wrist at $300 \%$ of perceptual threshold using a constant current generator. The stimulus duration was $0.2 \mathrm{~ms}$.

Short afferent inhibition. Three age-matched groups were examined, 6 healthy controls, 5 nontremulous patients (4 CIDP, 1 IgMPN), and 6 tremulous patients (4 CIDP, 2 IgMPN). Tremulous and nontremulous patients did not differ regarding age $(p=0.84)$, disease duration $(p=0.82)$, total sensory score $(p=0.63)$, MRC score $(p=0.90)$, or ONLS score $(p=0.44)$.

SAI was assessed as previously described. ${ }^{20} \mathrm{We}$ assessed the response to a cortical stimulus alone and when preceded by conditioning stimuli at 10 interstimulus intervals in reference to subjects' N20: $-18 \mathrm{~ms},-4 \mathrm{~ms},-2 \mathrm{~ms}, 0 \mathrm{~ms},+2 \mathrm{~ms},+4 \mathrm{~ms}$, $+6 \mathrm{~ms}$, $+8 \mathrm{~ms},+10 \mathrm{~ms},+18 \mathrm{~ms}$. Comparison of responses between groups was based on motor evoked potential (MEP) area.

Paired associative stimulation. Three age-matched groups were studied, including 6 healthy controls, 5 nontremulous patients (5 CIDP), and 8 tremulous patients (6 CIDP, 2 IgMPN). Tremulous and nontremulous patients did not differ regarding age $(p=0.61)$, disease duration $(p=0.72)$, total sensory score $(p=0.62)$, MRC score $(p=0.96)$, or ONLS score $(p=0.83)$.

A conditioning median nerve electrical stimulus was given $5 \mathrm{~ms}$ plus individual N20 (i.e., $25 \mathrm{~ms}$ if N20 latency was $20 \mathrm{~ms}$ ) before a TMS pulse over the APB muscle "hot spot" at an intensity predetermined to yield a $\sim 1 \mathrm{mV}$ resting MEP. Two hundred paired stimuli were delivered at a rate of $0.25 \mathrm{~Hz}^{21}$ Thirty MEPs were recorded before, immediately after, 15 minutes and 30 minutes after PAS. Comparison of PAS response was based on MEP area.

Data analysis and statistics. A Fourier analysis of signals derived from accelerometry was performed to define peak tremor frequency (PF). Total power of the spectra between 1 and $30 \mathrm{~Hz}$ was used as surrogate measure of tremor amplitude (TP). All parameters were calculated for each accelerometer axis, and then averaged. For EMG, the signal was full-wave rectified and smoothed and Fourier analysis was performed to derive PF.

For measurement of eyeblink conditioning, CRs were counted manually. EMG bursts were regarded as "alpha blinks" if their amplitude exceeded $50 \mu \mathrm{V}$ and if latency was $<200 \mathrm{~ms}$ after the CS. EMG bursts were regarded as CRs if latency was $>200 \mathrm{~ms}$ after the CS but before the US. For the CS only trials, EMG bursts occurring 200-600 ms after the CS were considered CRs. Statistical analysis was performed using PASW Statistics 18 (SPSS; Quarry Bay, Hong Kong). All post hoc comparisons were corrected by the Bonferroni method. The level of statistical significance was pre-set at $p<0.05$.

RESULTS Tremor recordings. In all 9 patients, a bilateral tremor was recorded during posture and action. Five patients had additional bilateral rest tremor. The power spectra of accelerometry and WE EMG showed corresponding peaks. Since there was no side-to-side difference in PF or TP in any position $(p>0.3)$, we used the mean of both sides for PF and TP for further analyses. Mean PF and TP in the 4 recorded conditions are shown in table 2 .

To compare PF and TP measured by accelerometry at rest, posture, and action, we computed 2 repeatedmeasures analyses of variance(ANOVA). For PF, there was no effect of condition $\left(F_{2,16}=3.47 ; p=0.06\right)$. For TP, there was an effect for condition $\left(F_{1,8}=6.76\right.$;

\section{Table 2 Mean (SD) PF and TP (derived from accelerometry) in the 4 recorded conditions}

\begin{tabular}{lll} 
& \multicolumn{2}{l}{ Accelerometry } \\
\cline { 2 - 3 } & PF (Hz) & TP (mG) \\
Rest & $7.1(1.6)$ & $0.55(1.65)$ \\
Posture & $6.1(1.6)$ & $0.85(2.41)$ \\
Weight & $6.4(1.4)$ & $1.21(2.48)$ \\
Action & $5.5(1.4)$ & $7.48(9.69)$ \\
\hline
\end{tabular}

Abbreviations: action $=$ repetitive finger-to-nose movements; PF = peak frequency; posture = arms outstretched; rest $=$ rest position; TP $=$ total power; weight $=$ arms outstretched with weight loading.

$p=0.03)$; however, post hoc comparisons showed no differences $(p>0.09)$.

A $t$ test for pairwise comparisons showed no difference in PF (accelerometry, WE EMG) before and after loading $(p>0.2)$, indicating that loading did not decrease tremor frequency. Five out of 9 patients had an increase of tremor amplitude after loading by at least $100 \%$. However, there was no difference regarding $\mathrm{TP}$ before and after loading $(p=0.33)$ on group level.

In 3 out of 9 patients ( 2 with IgMPN, 1 with MMNCB), PF in the APB was more than $1 \mathrm{~Hz}$ lower compared to the biceps. However, a paired $t$ test comparing PF during posture in biceps and APB in the whole group of patients showed no difference $(p=0.17)$.

Blink reflex and eyeblink classical conditioning. R2 blink reflex recovery curves, R1 and R2 latencies, and latency variability did not differ among the 3 groups.

Repeated-measures ANOVA with block (7) as within-subject factor and group (3) as between-subject factor revealed an interaction of block $\times$ group $\left(F_{12,132}=3.34, p<0.001\right)$. There were also effects of block $\left(F_{6,132}=12.2, p<0.001\right)$ and group $\left(F_{2,22}=16.6, p<0.001\right)$ (figure 1$)$. Post hoc tests showed that tremulous patients had a lower rate of CRs as the blocks progressed compared to healthy controls and nontremulous patients $(p<0.001)$. This difference was significant in conditioning blocks 3-7 (figure 1). Latencies of CRs, spontaneous blink rates, and "alpha blinks" were not different between the groups.

SAI. Repeated-measures ANOVA with state (11) as within-subjects factor and group (3) as between-subjects factor showed an effect of state $\left(F_{3,48}=6.64\right.$; $p<0.001)$. There was no effect of group or the group $X$ state interaction. Post hoc tests showed a reduction in MEP size occurring at interstimulus intervals of $\mathrm{N} 20(p<0.001)$ and N20-2 $(p=$ 0.007) (figure 2). 
Figure 1 Eyeblink classical conditioning in the 3 groups

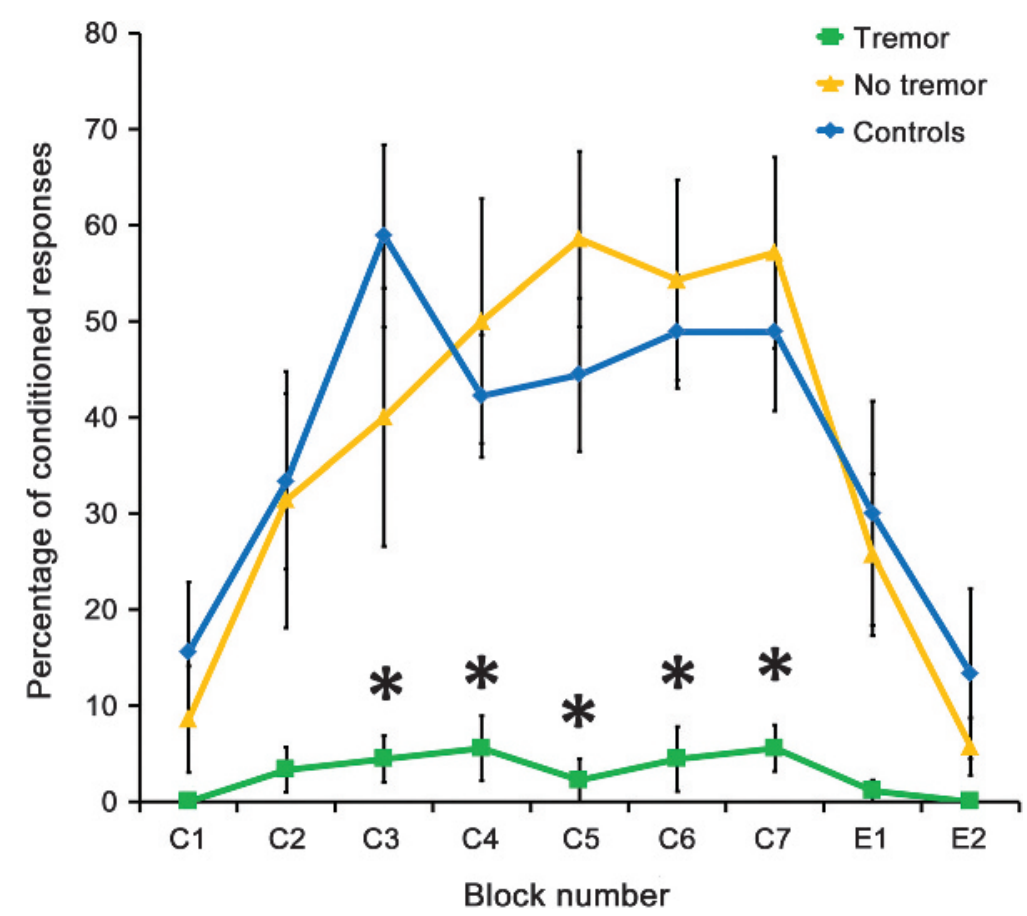

Mean percentage of conditioned responses of each group of subjects over the 7 conditioning blocks (C1-C7). E1 and E2 represent extinction blocks. Error bars represent standard error. "Significantly lower rate of conditioned blink responses in tremulous patients compared to healthy controls and to nontremulous patients.

PAS. Mean intensity to produce $1 \mathrm{mV}$ MEPs was not different between patients (56\%) and controls (61\%). Repeated-measures ANOVA with time (4) and muscle (3) as within-subject factors and group (3) as

\section{Figure 2 Short afferent inhibition in the 3 groups}

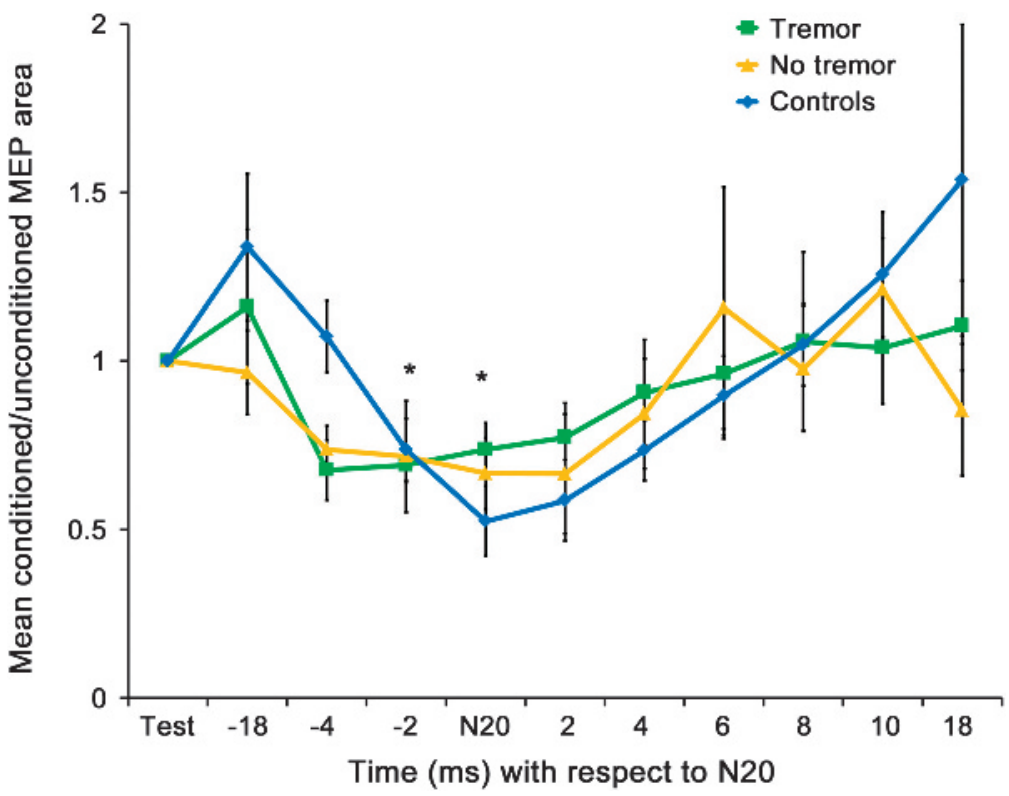

Effect of short afferent inhibition on mean conditioned/unconditioned motor evoked potential (MEP) area. *Significant inhibition at N2O and N2O-2 ms among all groups. Relative values are used for the figure. Error bars represent standard error. between-subject factor revealed that PAS produced a lasting increase in mean MEP area demonstrated by an effect of time $\left(F_{2,33}=4.762, p=0.014\right)$. The size of MEP facilitation differed among groups and muscles, indicated by an effect of group $\left(F_{2,16}=\right.$ $9.890, p=0.002)$ and an interaction of time $\times$ group $\left(F_{4,33}=5.166, p=0.002\right)$. The interaction between time $\times$ muscle $\times$ group $\left(F_{8,62}=3.436, p=0.003\right)$ demonstrates that the effect of PAS on the homotopically (APB) and heterotopically (FDI, ADM) conditioned muscles differed time-dependently between groups (figure 3).

To further explore the conditioning effects of PAS on MEP areas in each group, we computed separate repeated-measures ANOVAs with time and muscle as within-subject factors. In controls, an effect of time $\left(F_{3,15}=3.212 ; p=0.047\right)$ was found. The facilitatory effect was stronger in the APB compared to the FDI/ $\mathrm{ADM}$, reflected by a strong time $\times$ muscle interaction $\left(F_{6,30}=7.257 ; p<0.001\right)$. In patients without tremor, a different pattern of PAS-induced changes occurred. MEP facilitation was higher and spatial specificity was compromised as indicated by a main effect of time $\left(F_{3,12}=6.570 ; p=0.007\right)$ without time $\times$ muscle interaction. Patients with tremor had an effect of time $\left(F_{3,21}=3.479 ; p=0.034\right)$ due to overall MEP depression without time $\times$ muscle interaction.

Post hoc comparisons revealed that PAS induced an increase in MEP areas compared to baseline in the APB in controls (T15: $p=0.023$ ), but not in neuropathy with and without tremor. A facilitation of the MEP area in the $\mathrm{ADM}$ and FDI was only observed in patients without tremor (T15 [FDI]: $p=0.003$; $\mathrm{T} 15[\mathrm{ADM}]: p=0.036)$.

DISCUSSION We demonstrate that patients with inflammatory neuropathy and tremor differ from patients without tremor with regard to cerebellar function and sensorimotor plasticity. We found very low rates of EBCC in patients with inflammatory neuropathy and tremor compared to nontremulous patients and healthy controls, suggesting abnormal associative learning in the cerebellum that segregates with tremor. We also describe an absence of normal facilitation in TMS-evoked EMG potentials after PAS in patients with tremor, suggesting abnormal sensorimotor cortex plasticity. In nontremulous patients, sensorimotor plasticity, demonstrated by facilitation of TMS-evoked EMG potentials after PAS, occurred in neighboring muscles but without a normal facilitatory response in the target muscle, suggesting a lack of topographic specificity of sensorimotor plasticity.

Tremor in our patients with inflammatory neuropathies was invariably present during posture and action. Five patients had additional rest tremor. When present in all 3 conditions, tremor was worst 
Figure $3 \quad$ Paired associative stimulation in the 3 groups
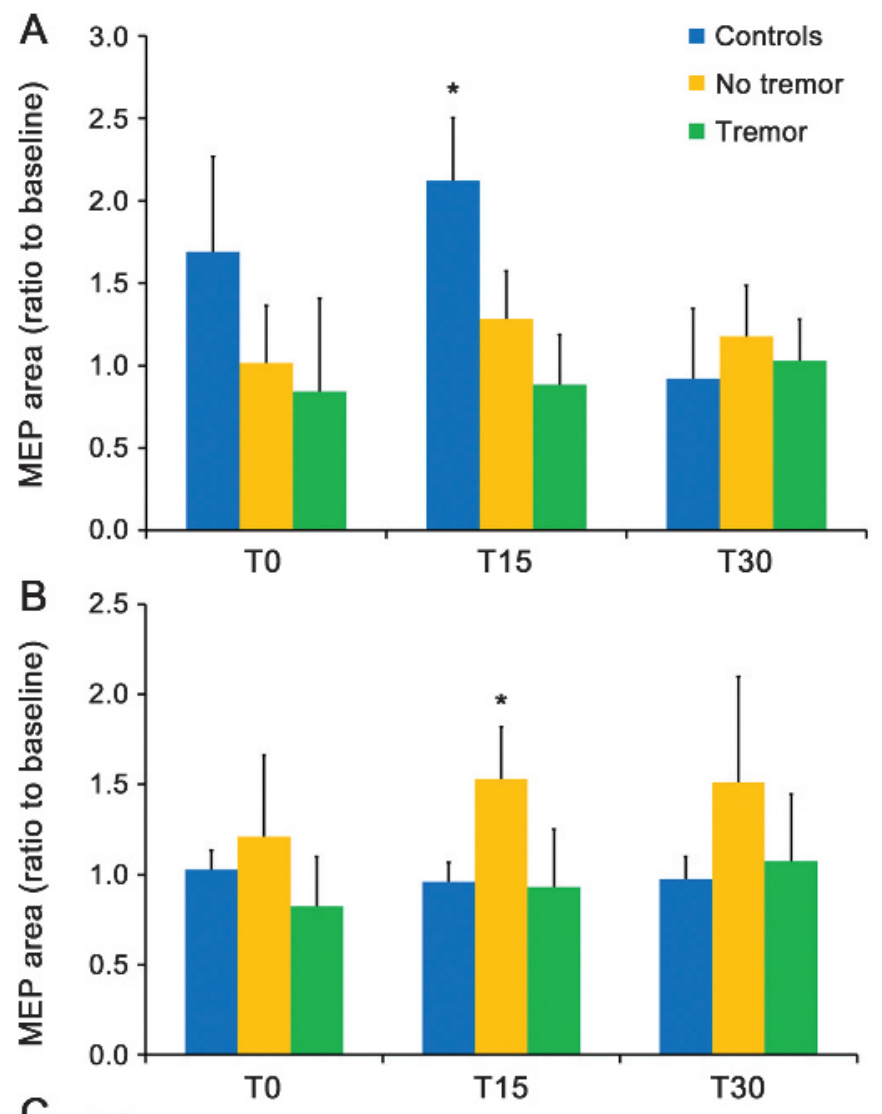

C

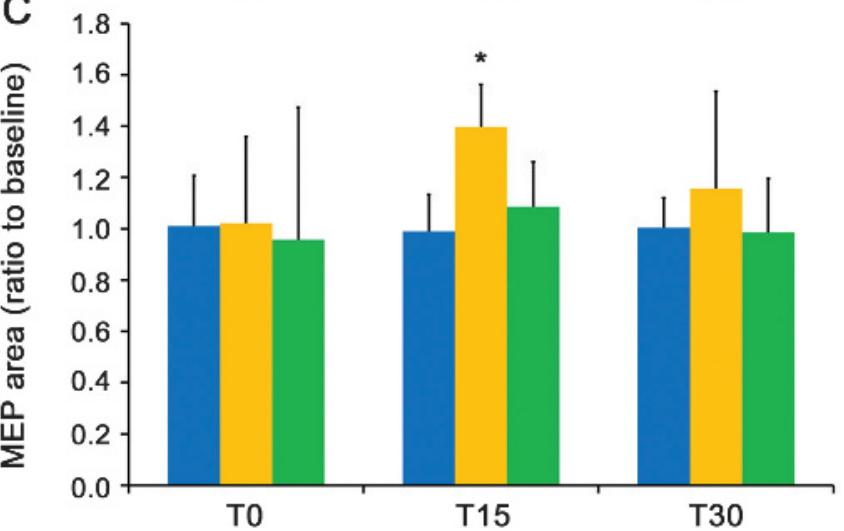

Effect of paired associative stimulation (PAS) on mean motor evoked potential (MEP) areas in healthy controls (white), patients with inflammatory neuropathies without tremor (gray), and patients with inflammatory neuropathies with tremor (black). The data are plotted as a ratio to the baseline MEP area. Error bars represent standard deviation. Ratios higher than 1 indicate facilitation and ratios below 1 indicate inhibition of MEP area. The effect of PAS on MEP area for the abductor pollicis brevis (target) muscle (A), on the first dorsal interossei (B), and on the abductor digiti minimi (C). ${ }^{*} p<0.05$ paired $t$ test comparing MEP area with baseline (corrected for multiple comparisons by Bonferroni method).

during posture or action, which is in concordance with previous reports. ${ }^{8,22}$ Previously, a lower tremor frequency in distal compared to proximal hand muscles in 2 out of 6 patients with paraproteinemic neuropathy was described. ${ }^{8}$ This was also observed in 3 of our patients. However, on a group level, the peak tremor frequency did not differ between proximal and distal muscles.
EBCC is a form of simple associative learning that is well-studied and for which the cerebellum is both necessary and sufficient. Structural or functional impairments of the cerebellum lead to abnormalities in acquisition of this conditioned response. ${ }^{17,18,23,24}$ We demonstrate abnormal EBCC in tremulous neuropathy patients that clearly differentiates them from the normal rates of conditioning in nontremulous neuropathy patients and controls. Mean R1 and R2 latencies and latency variability did not differ between groups, making it unlikely that desynchronization of the afferent volley alone may be a factor in the lack of conditioned responses in the tremulous patients. The degree of impairment of acquisition of conditioned responses reported here is in line with the degree of impairment reported in patients with cerebellar degeneration or cerebellar lesions. A previous study showed a delayed second agonist burst ${ }^{25}$ in patients with IgMPN and tremor, suggesting that the cerebellum, although intact, would be a likely candidate for a central processor "tricked" into generating tremor in the context of distorted mistimed peripheral signals. ${ }^{8}$ Our data instead provide evidence that the cerebellum is not functioning normally in those patients who develop tremor.

We were able to record somatosensory evoked potentials, albeit delayed, in all CIDP or IgMPN patients with tremor. This is in line with the assertion that tremor occurs in the presence of distorted rather than absent sensory input. ${ }^{8}$ All patients, tremulous and nontremulous, had normal SAI as compared with normal controls. This suggests that despite the peripheral sensory-motor delay due to the demyelinating neuropathies, central processes have, remarkably, been able to adapt to such delays to reset to the new latency of the N20.

In healthy subjects, PAS causes a facilitation of motor evoked potentials in the "target muscle" only, lasting for 15-30 minutes. This response shares a number of features with long-term potentiation. ${ }^{19}$ Patients with tremor showed no response to PAS. The normal SAI in patients with tremor argues against afferent dysfunction and associated changes in the sensory motor cortex as sole explanation for the abnormal PAS response. This is supported by the findings in one tremulous CIDP patient with normal N20 and absent PAS response. In recent work, we have demonstrated that cerebellar suppression in healthy subjects by transcranial direct current stimulation impairs subsequent motor cortical facilitation by PAS. ${ }^{26}$ We therefore speculate that the absent PAS response in tremulous neuropathy patients may reflect cerebellar dysfunction that is also responsible for their impaired EBCC.

In patients without tremor, PAS response was also abnormal. Facilitatory changes were seen but these occurred in neighboring ulnar-innervated muscles 
but not in the APB. This latter finding has not, to our knowledge, previously been described in any other group of subjects. It is conceivable that altered topographic representation triggered by the neuropathy may affect sensory-motor integration required to mediate changes associated with PAS. ${ }^{27,28}$ An additional speculation is that this unusual response to PAS may be explained by a peripheral phenomenon such as ephaptic transmission between peripheral nerve fibers.

We present evidence that tremor in patients with inflammatory neuropathy is associated with cerebellar dysfunction. We acknowledge that generalizability is limited by our relatively small sample size. Also, this study does not answer the question whether the cerebellar abnormalities in tremulous patients are secondary to the presence of tremor or primary. Regarding the latter, one possibility is that in those with tremor, the specific antibody involved in causing the peripheral neuropathy is capable of crossing the blood-brain barrier and binding to the cerebellum. There is indirect evidence for this in IgMPN, in which tremor is typical. It would be of interest to look for evidence of antibodies that bind to cerebellum in tremulous patients with CIDP: they may share a common causative antibody for their neuropathy and the cerebellar dysfunction that drives the development of tremor.

\section{AUTHOR CONTRIBUTIONS}

P.S., T.A.S., P.K.-W., M.M.R., M.P.L., M.A., K.P.B., J.C.R., M.J.E.: conception or design of the study. P.S., T.A.S., P.K.-W., M.A., J.C.R., M.J.E.: analysis or interpretation of the data. P.S., T.A.S., P.K.-W., M.M.R., M.P.L., H.M., R.S., K.P.B., J.C.R., M.J.E.: drafting or revising the manuscript for intellectual content.

\section{STUDY FUNDING}

T.A.S. was funded by the National Institute for Health Research (UK) (DRF-2009-02-121).

\section{DISCLOSURE}

P. Schwingenschuh received funding to attend conferences from Boehringer Ingelheim, GlaxoSmithKline, Ipsen, Novartis, UCB, and Merz pharma companies; received speaker honoraria from UCB; and served on national advisory boards of UCB and Novartis. T. Saifee is funded by the National Institute of Health Research, UK. He has received funding to attend conferences from UCB and Ipsen. P. Katschnig-Winter received funding to attend conferences from Boehringer Ingelheim, GlaxoSmithKline, Novartis, UCB, Bayer, and Merz pharma companies. M. Reilly, M. Lunn, H. Manji, and M. Aguirregomozcorta report no disclosures. R. Schmidt received speaker honoraria from Pfizer, Novartis, Janssen, Lundbeck, and Merz; served on scientific advisory boards for Pfizer, Novartis, Janssen, Lundbeck, Merz, Austroplant, GE Healthcare, and Probiodrug. K. Bhatia received funding for travel from GlaxoSmithKline, Orion Corporation, Ipsen, and Merz Pharmaceuticals, LLC; serves on the editorial boards of Movement Disorders and Therapeutic Advances in Neurological Disorders; received speaker honoraria from GlaxoSmithKline, Ipsen, Merz Pharmaceuticals, LLC, and Sun Pharmaceutical Industries Ltd.; received personal compensation for scientific advisory board for GSK and Boehringer Ingelheim; received research support from Ipsen and from the Halley Stewart Trust through Dystonia Society UK; and received the Wellcome Trust MRC strategic neurodegenerative disease initiative award (ref. number WT089698), a grant from Parkinson's UK (ref. number G-1009), and a grant from the Dystonia Coalition. J. Rothwell receives grants from the Dystonia Medical Research
Foundation and has received speaking honoraria from the Movement Disorders Society. M. Edwards receives grant funding from the National Institute of Health Research, UK, Parkinson's UK, and the UK Dystonia Society. He has received speaking honoraria from the Movement Disorders Society and UCB. Go to Neurology.org for full disclosures.

Received September 25, 2012. Accepted in final form January 31, 2013.

\section{REFERENCES}

1. Lunn MP, Willison HJ. Diagnosis and treatment in inflammatory neuropathies. J Neurol Neurosurg Psychiatry 2009; 80:249-258.

2. Smith IS, Kahn SN, Lacey BW, et al. Chronic demyelinating neuropathy associated with benign IgM paraproteinaemia. Brain 1983;106:169-195.

3. Smith IS. The natural history of chronic demyelinating neuropathy associated with benign IgM paraproteinaemia: a clinical and neurophysiological study. Brain 1994;117: 949-957.

4. Ahlskog MC, Kumar N, Mauermann ML, Klein CJ. IgMmonoclonal gammopathy neuropathy and tremor: a first epidemiologic case control study. Parkinsonism Relat Disord 2012;18:748-752.

5. Saifee TA, Schwingenschuh P, Reilly MM, et al. Tremor in inflammatory neuropathies. J Neurol Neurosurg Psychiatry. Epub 2012 Sept 5.

6. Stanton M, Pannoni V, Lewis RA, et al. Dispersion of compound muscle action potential in hereditary neuropathies and chronic inflammatory demyelinating polyneuropathy. Muscle Nerve 2006;34:417-422.

7. Kiers L, Clouston P, Zuniga G, Cros D. Quantitative studies of $\mathrm{F}$ responses in Guillain-Barre syndrome and chronic inflammatory demyelinating polyneuropathy. Electroencephalogr Clin Neurophysiol 1994;93:255-264.

8. Bain PG, Britton TC, Jenkins IH, et al. Tremor associated with benign IgM paraproteinaemic neuropathy. Brain 1996;119:789-799.

9. Boecker H, Brooks DJ. Functional imaging of tremor. Mov Disord 1998;13(suppl 3):64-72.

10. Smith IS. Tremor in peripheral neuropathy. In: Findley LJ, Koller WC, eds. Handbook of Tremor Disorders. New York: Marcel Dekker, Inc.; 1995:12.

11. Dalakas MC, Teravainen H, Engel WK. Tremor as a feature of chronic relapsing and dysgammaglobulinemic polyneuropathies: incidence and management. Arch Neurol 1984;41:711-714.

12. Dalakas MC, Engel WK. Chronic relapsing (dysimmune) polyneuropathy: pathogenesis and treatment. Ann Neurol 1981;9(suppl):134-145.

13. Fahn S, Tolosa E, Concepcion M. Clinical rating scale for tremor. In: Jankovic J, Tolosa E, eds. Parkinson's Disease and Movement Disorders, 2nd ed. Baltimore: Williams \& Wilkins; 1993:231-280.

14. Kleyweg RP, van der Meche FG, Schmitz PI. Interobserver agreement in the assessment of muscle strength and functional abilities in Guillain-Barre syndrome. Muscle Nerve 1991;14:1103-1109.

15. Teunissen LL, Notermans NC, Franssen H, et al. Differences between hereditary motor and sensory neuropathy type 2 and chronic idiopathic axonal neuropathy: a clinical and electrophysiological study. Brain 1997;120: 955-962.

16. Graham RC, Hughes RA. A modified peripheral neuropathy scale: the Overall Neuropathy Limitations Scale. J Neurol Neurosurg Psychiatry 2006;77:973-976. 
17. Schwingenschuh P, Katschnig P, Edwards MJ, et al. The blink reflex recovery cycle differs between essential and presumed psychogenic blepharospasm. Neurology 2011; 76:610-614.

18. Bracha V, Zhao L, Wunderlich DA, Morrissy SJ, Bloedel JR. Patients with cerebellar lesions cannot acquire but are able to retain conditioned eyeblink reflexes. Brain 1997;120:1401-1413.

19. Stefan K, Kunesch E, Cohen LG, Benecke R, Classen J. Induction of plasticity in the human motor cortex by paired associative stimulation. Brain 2000;123:572-584.

20. Tokimura H, Di Lazzaro V, Tokimura Y, et al. Short latency inhibition of human hand motor cortex by somatosensory input from the hand. J Physiol 2000;523:503513.

21. Schwingenschuh P, Ruge D, Edwards MJ, et al. Distinguishing SWEDDs patients with asymmetric resting tremor from Parkinson's disease: a clinical and electrophysiological study. Mov Disord 2010;25:560-569.

22. Pedersen SF, Pullman SL, Latov N, Brannagan TH III. Physiological tremor analysis of patients with anti-myelin- associated glycoprotein associated neuropathy and tremor. Muscle Nerve 1997;20:38-44.

23. Hoffland BS, Bologna M, Kassavetis P, et al. Cerebellar theta burst stimulation impairs eye-blink classical conditioning. J Physiol 2011;590:887-897.

24. Christian KM, Thompson RF. Neural substrates of eyeblink conditioning: acquisition and retention. Learn Mem 2003;10:427-455.

25. Berardelli A, Hallett M, Rothwell JC, et al. Single-joint rapid arm movements in normal subjects and in patients with motor disorders. Brain 1996;119:661-674.

26. Hamada M, Strigaro G, Murase N, et al. Cerebellar modulation of human associative plasticity. J Physiol 2012; 590:2365-2374.

27. Freund P, Weiskopf N, Ward NS, et al. Disability, atrophy and cortical reorganization following spinal cord injury. Brain 2011;134:1610-1622.

28. Freund P, Rothwell J, Craggs M, Thompson AJ, Bestmann S. Corticomotor representation to a human forearm muscle changes following cervical spinal cord injury. Eur J Neurosci 2011;34:1839-1846.

\section{Do You Know What is Happening to Neurology on Capitol Hill?}

Congress is making decisions that affect neurologic research funding and the way neurology is practiced in the United States. Only Capitol Hill Report on AAN.com takes you behind Washington's closed doors and shines a light on how your federal legislators are working for-or against—your interests. Read Capitol Hill Report on AAN.com the second and fourth Wednesday of each month. Stay informed. Your work depends on it. 


\section{Neurology}

Cerebellar learning distinguishes inflammatory neuropathy with and without tremor Petra Schwingenschuh, Tabish A. Saifee, Petra Katschnig-Winter, et al. Neurology 2013;80;1867-1873 Published Online before print April 17, 2013

DOI 10.1212/WNL.0b013e318292a2b8

This information is current as of April 17, 2013

\begin{tabular}{|c|c|}
\hline $\begin{array}{l}\text { Updated Information \& } \\
\text { Services }\end{array}$ & $\begin{array}{l}\text { including high resolution figures, can be found at: } \\
\text { http://n.neurology.org/content/80/20/1867.full }\end{array}$ \\
\hline Supplementary Material & $\begin{array}{l}\text { Supplementary material can be found at: } \\
\text { http://n.neurology.org/content/suppl/2013/04/17/WNL.0b013e318292a } \\
\text { 2b8.DC1 }\end{array}$ \\
\hline References & $\begin{array}{l}\text { This article cites } 25 \text { articles, } 4 \text { of which you can access for free at: } \\
\text { http://n.neurology.org/content/80/20/1867.full\#ref-list- } 1\end{array}$ \\
\hline Citations & $\begin{array}{l}\text { This article has been cited by } 1 \text { HighWire-hosted articles: } \\
\text { http://n.neurology.org/content/80/20/1867.full\#\#therarticles }\end{array}$ \\
\hline Subspecialty Collections & $\begin{array}{l}\text { This article, along with others on similar topics, appears in the } \\
\text { following collection(s): } \\
\text { All Clinical Neurology } \\
\text { http://n.neurology.org/cgi/collection/all_clinical_neurology } \\
\text { EMG } \\
\text { http://n.neurology.org/cgi/collection/emg } \\
\text { Tremor } \\
\text { http://n.neurology.org/cgi/collection/tremor }\end{array}$ \\
\hline Permissions \& Licensing & $\begin{array}{l}\text { Information about reproducing this article in parts (figures,tables) or in } \\
\text { its entirety can be found online at: } \\
\text { http://www.neurology.org/about/about_the_journal\#permissions }\end{array}$ \\
\hline Reprints & $\begin{array}{l}\text { Information about ordering reprints can be found online: } \\
\text { http://n.neurology.org/subscribers/advertise }\end{array}$ \\
\hline
\end{tabular}

Neurology ${ }^{\circledR}$ is the official journal of the American Academy of Neurology. Published continuously since 1951, it is now a weekly with 48 issues per year. Copyright () 2013 American Academy of Neurology. All rights reserved. Print ISSN: 0028-3878. Online ISSN: 1526-632X.

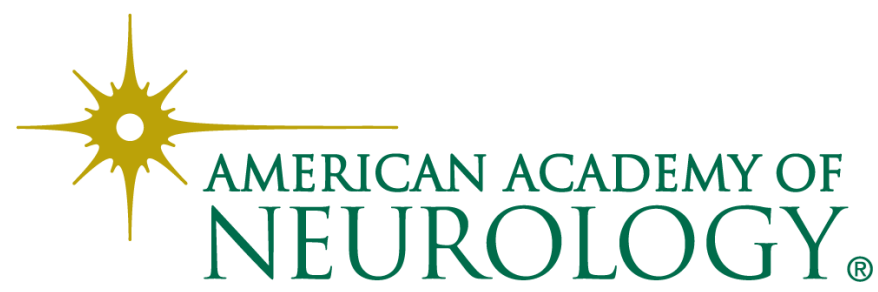

